\title{
Adrenal crisis in a 14-year-old boy 12 years after hematopoietic stem cell transplantation
}

\author{
Theresa Penger1, Andrea Albrecht1, Michaela Marx', Daniel Stachel2, Markus Metzler² \\ and Helmuth G Dörr ${ }^{1}$
}

Divisions of ${ }^{1}$ Pediatric Endocrinology and 2 Pediatric Hematology \& Oncology, Department of Pediatric and Adolescent

Medicine, University Hospital of Erlangen, Erlangen, Germany

\author{
Correspondence \\ should be addressed \\ to H G Dörr \\ Email \\ helmuth-guenther.doerr@ \\ uk-erlangen.de
}

\section{Summary}

We report on a boy of Albanian descent with the history of juvenile myelomonocytic leukemia (JMML). JMML was diagnosed at the age of 17 months and treated by hematopoietic stem cell transplantation (HSCT). At the age of 14.3 years, about 12 years after $\mathrm{HSCT}$, he was hospitalized with an adrenal crisis. Hormone findings were consistent with primary adrenal insufficiency. Autoimmune adrenalitis was confirmed by positive autoantibodies against 21-hydroxylase and adrenal tissue. Since autoimmune Hashimoto thyroiditis was already known from the age of 9 years, we assume that both diseases are part of the spectrum of autoimmune polyglandular syndrome (APS) type 2. APS type 2 is a rare endocrine disease characterized by Addison's disease along with autoimmune thyroid disease and/or type 1 diabetes.

\section{Learning points:}

- Endocrine sequelae after hematopoietic stem cell transplantation (HSCT) are common and can develop over a long period.

- Primary adrenal insufficiency after HSCT is absolutely rare.

- The combination of adrenal autoimmune disease and Hashimoto thyroiditis is consistent with autoimmune polyglandular syndrome type 2 .

\section{Background}

Long-term survivors of pediatric hematopoietic stem cell transplantation (HSCT) are at risk for late morbidity and mortality $(1,2,3)$. Endocrine late effects including pituitary, adrenal, thyroid and gonadal dysfunctions are common and can develop over a long period $(4,5,6,7$, 8 ). These sequelae are influenced by various factors such as the underlying pathological condition, the treatment regimen for the disease and the used therapeutic regimen before HSCT. Secondary adrenal insufficiency (SAI) is the most common form of adrenal insufficiency and mainly related to the duration and cumulative dose of corticosteroid treatment after HSCT (9). For example, SAI was reported in four subjects, who had been treated with corticosteroids for $\geq 10$ months for chronic graft-versus- host disease (GvHD) (10). It was also speculated that the age at HSCT might be an additional risk factor since late effects were more common in young children (2).

Reports on primary adrenal insufficiency (PAI) are extremely rare. To the best of our knowledge, we found only three reports on PAI in children after HSCT in the literature $(11,12,13)$. In this report, we present the case of a boy with PAI and autoimmune adrenalitis after HSCT.

\section{Case presentation}

At the age of 17 months, the boy of Albanian descent was diagnosed with juvenile myelomonocytic leukemia (JMML). He was treated with allogenic HSCT at the 
age of 19 months after myeloablative conditioning chemotherapy with busulfan, cyclophosphamide, melphalan and antithymocyte immunoglobulin. Two months after HSCT, he developed a fulminant relapse of JMML. In order to induce a graft-versus-leukemia effect, all immunosuppressive drugs were stopped. Within weeks, life threatening GvHD of skin and gut developed. Concomitantly, the JMML disappeared. The boy was treated with 6-mercaptopurine until the age of 26 months in an attempt to control both the leukemia and the GvHD. The patient could be discharged and remains free of active GvHD and leukemia to this date. Thereafter, yearly follow-up visits were performed at our oncological outpatient clinic.

At the age of 9 years, he developed subclinical hypothyroidism and goiter. High thyroid autoantibodies led to the diagnosis of Hashimoto thyroiditis. At the age of 14.3 years, a routine follow-up was performed. At this time, the boy was in good clinical condition. Two weeks later, he was admitted to our hospital with complaints of nausea and weight loss of $1.3 \mathrm{~kg}$. Fever was not reported.

The laboratory work up at emergency hospitalization showed low serum levels of sodium, high serum potassium levels, low-normal serum cortisol levels, in contrast to markedly elevated plasma adrenocorticotrophic hormone (ACTH) and serum renin levels. Clinical and laboratory data are shown in Table 1. The diagnosis of autoimmune adrenalitis was confirmed by positive adrenal autoantibodies and antibodies against 21-hydroxylase.

Therapy for adrenal crisis started with intravenous administration of hydrocortisone together with appropriate fluid substitution including $0.9 \%$ saline. After $24 \mathrm{~h}$, therapy was shifted to oral substitution of hydrocortisone and fludrocortisone. The patient was discharged from hospital after 4 days in a good clinical condition.

\section{Discussion}

Endocrine dysfunctions such as growth hormone deficiency, hypogonadism, adrenal insufficiency and hypothyroidism have been reported in long-term survivors of pediatric HSCT for malignant diseases $(9,14$, $15,16,17)$. It has been suggested to classify the endocrine sequelae as hormonal deficiencies, autoimmune diseases, secondary tumors or metabolic complications (18).

SAI due to the suppression of the hypothalamopituitary axis after long-term corticosteroid is the most common form of adrenal insufficiency. Corticotropin deficiency can also be caused by total body irradiation.
Table 1 Clinical and laboratory data.

\begin{tabular}{|c|c|c|}
\hline & $\begin{array}{l}\text { Last outpatient } \\
\text { visit }\end{array}$ & $\begin{array}{l}\text { Adrenal crisis } \\
\text { (2 weeks later) }\end{array}$ \\
\hline \multicolumn{3}{|l|}{ Clinical data } \\
\hline General & Good condition & $\begin{array}{l}\text { Reduced } \\
\text { condition, } \\
\text { nausea, weight } \\
\text { loss }\end{array}$ \\
\hline $\mathrm{RR}(\mathrm{mmHg})$ & $122 / 76$ & $99 / 61$ \\
\hline $\mathrm{HR}(/ \mathrm{min})$ & 73 & 116 \\
\hline \multicolumn{3}{|l|}{ Auxological data } \\
\hline Height (cm) & 165.5 (-0.4 SDS) & 165.5 \\
\hline Weight (kg) & 46.8 & 45.5 \\
\hline $\mathrm{BMI}$ & $\begin{array}{l}17.1 \mathrm{~kg} / \mathrm{m}^{2}(-0.9 \\
\text { SDS })\end{array}$ & $\begin{array}{l}16.6 \mathrm{~kg} / \mathrm{m}^{2}(-1.3 \\
\text { SDS })\end{array}$ \\
\hline $\begin{array}{l}\text { Tanner pubertal } \\
\text { stage }\end{array}$ & $\begin{array}{l}\mathrm{pH} \mathrm{3,} \mathrm{testes} \mathrm{sizes} \\
(\mathrm{mL}) 8 / 8\end{array}$ & \\
\hline Serum $\mathrm{Na}(\mathrm{mmol} / \mathrm{L})$ & $133(132-141)$ & $114(132-141)$ \\
\hline Serum K (mmol/L) & $4.2(3.3-4.6)$ & $6.0(3.3-4.6)$ \\
\hline $\begin{array}{l}\text { Cortisol }(\mathrm{nmol} / \mathrm{L}) \\
08: 00-10: 00 \mathrm{~h}\end{array}$ & $151(<138)$ & $264(<138)$ \\
\hline Plasma ACTH (pg/mL) & ND & $625(<60)$ \\
\hline $\operatorname{Renin}(p g / m L)$ & ND & $2550(<75)$ \\
\hline \multicolumn{3}{|l|}{ Antibodies } \\
\hline $\mathrm{Tg}$ & $2000 \mathrm{U} / \mathrm{mL}(<60)$ & \\
\hline TPO & $1941 \mathrm{U} / \mathrm{mL}(<60)$ & \\
\hline 21-Hydroxylase & & $57.6(<10)$ \\
\hline Adrenal cortex & & $1: 32(<1: 10)$ \\
\hline
\end{tabular}

Reference values are shown in brackets.

$\mathrm{ACTH}$, adrenocorticotrophic hormone; HR, heart rate; ND, not determined; Tg, thyroglobulin; TPO, thyroidal peroxidase.

PAI or Addison's disease due to destruction of the adrenal cortex by cell-mediated immune mechanisms is rare $(19,20)$. The occurrence of Addison's disease with autoimmune thyroid disease and/or type 1 diabetes mellitus is known as autoimmune polyglandular syndrome type 2 (APS-2) (21). SAI is characterized by inadequate production of glucocorticoids, whereas PAI is characterized by inadequate production of glucocorticoids and mineralocorticoids. PAI is often diagnosed at the occasion of an adrenal crisis with nonspecific symptoms $(19,20,22)$.

Two weeks before adrenal crisis, our patient was seen in our outpatient clinic in a good condition. At that time, a low-normal cortisol level was measured. The clinical signs that led to emergency hospitalization were nausea, hypotension and weight loss. Laboratory data of low serum sodium and potassium levels, elevated plasma ACTH and serum renin levels together with low-normal cortisol levels was consistent with PAI. Autoimmune Addison's disease was confirmed by positive adrenal and steroid 21-hydroxylase autoantibodies (23). Antibodyassociated organ-specific autoimmune diseases after HSCT have been reported in the literature for many years. 
Most common presentations are autoimmune cytopenias, Hashimoto thyroiditis or myasthenia gravis $(24,25,26,27,28)$. Multiple autoantibodies have been associated with chronic GvHD $(29,30)$. Assessing the prevalence of autoimmune diseases after HSCT, it has to be considered that HSCT is a curative treatment for both malignant diseases and many nonmalignant disorders, such as autoimmune diseases (31). The cumulative incidence of secondary autoimmune disease after HSCT for primary autoimmune disease was 9.8\% at 5 years (32). It has been speculated that dysregulation of the immune system after HSCT might trigger the development of autoimmune diseases $(33,34)$.

Reports on PAI are extremely rare. We identified only three children with PAI after HSCT in the literature $(11,12$, 13). PAI was reported in a 9-year-old girl approximately 20 months after HSCT for myelodysplastic syndrome (11). The etiology for PAI was unclear; particularly, there was no evidence of autoimmune adrenalitis. PAI due to autoimmune adrenalitis was reported in a 10-year-old boy with familial Wiskott-Aldrich syndrome after bone marrow transplantation at the age of 9 months (13). PAI due to autoimmune adrenalitis was also diagnosed in an 11-year-old boy with homozygous sickle cell disease after allogeneic bone marrow transplant from his father (12). The symptoms of the father and his son occurred at the same time, suggesting disease transfer by pathogenic donor cells. In this case, autoimmune adrenalitis was identified as part of APS-2. Moreover, APS-3 (combination of autoimmune thyroid disorder and type 1 diabetes mellitus) has been diagnosed after haploidentical HSCT in a child with acute myeloid leukemia (21).

In our patient, Hashimoto thyroiditis was diagnosed at the age of 9 years and autoimmune adrenalitis at the age of 14.3 years. The co-occurrence of Hashimoto thyroiditis and autoimmune adrenalitis is consistent with the diagnosis of APS-2. Currently, the patient has no clinical evidence of type 1 diabetes; in particular, pancreas islet cell antibodies or antibodies to glutamic acid decarboxylase were negative. There is no family history of autoimmune disease, and APS-2 was not the result of the transplantation, because the donor was not affected. Currently, we cannot exclude that the connection between the HSCT and the development of Hashimoto thyroiditis and autoimmune adrenalitis might be coincidental. However, we can also not exclude that this connection exists. In conclusion, we report a rare autoimmune disease which developed 12 years after HSCT.
Declaration of interest

The authors declare that there is no conflict of interest that could be perceived as prejudicing the impartiality of the research reported.

\section{Funding}

This research did not receive any specific grant from any funding agency in the public, commercial or not-for-profit sector.

Patient consent

Patient and mother were informed about this publication.

\section{Author contribution statement}

All authors contributed to the design of the work, analysis and interpretation of data, drafting the work and final approval of the version to be published. The case was presented in part as Poster at the 55th Annual Meeting of the ESPE 2016 in Paris.

\section{References}

1 Schechter T, Pole JD, Darmawikarta D, Doyle J, Ali M, Egeler M, Gassas A, Irwin MS, Greenberg M \& Nathan PC. Late mortality after hematopoietic SCT for a childhood malignancy. Bone Marrow Transplantation 201348 1291-1295. (https://doi.org/10.1038/ bmt.2013.64)

2 Bresters D, van Gils IC, Kollen WJ, Ball LM, Oostdijk W, van der Bom JG \& Egeler RM. High burden of late effects after haematopoietic stem cell transplantation in childhood: a singlecentre study. Bone Marrow Transplantation 201045 79-85. (https:// doi.org/10.1038/bmt.2009.92)

3 Wilhelmsson M, Vatanen A, Borgström B, Gustafsson B, Taskinen M, Saarinen-Pihkala UM, Winiarski J \& Jahnukainen K. Adverse health events and late mortality after pediatric allogeneic hematopoietic SCT-two decades of longitudinal follow-up. Bone Marrow Transplantation 201550 850-857. (https://doi.org/10.1038/ bmt.2015.43)

4 Legault L \& Bonny Y. Endocrine complications of bone marrow transplantation in children. Pediatric Transplantation 19993 60-66. (https://doi.org/10.1034/j.1399-3046.1999.00009.x)

5 Jung MH, Cho KS, Lee JW, Chung NG, Cho B, Suh BK, Kim HK \& Lee BC. Endocrine complications after hematopoietic stem cell transplantation during childhood and adolescence. Journal of Korean Medical Science 200924 1071-1077. (https://doi.org/10.3346/ jkms.2009.24.6.1071)

6 Orio F, Muscogiuri G, Palomba S, Serio B, Sessa M, Giudice V, Ferrara I, Tauchmanovà L, Colao A \& Selleri C. Endocrinopathies after allogeneic and autologous transplantation of hematopoietic stem cells. Scientific World Journal 20142014 282147. (https://doi. org/10.1155/2014/282147)

7 Pulsipher MA, Skinner R, McDonald GB, Hingorani S, Armenian SH Cooke KR, Gracia C, Petryk A, Bhatia S, Bunin N, et al. National Cancer Institute, National Heart, Lung and Blood Institute/Pediatric Blood and Marrow Transplantation Consortium First International Consensus Conference on late effects after pediatric hematopoietic cell transplantation: the need for pediatric-specific long-term follow-up guidelines. Biology of Blood and Marrow Transplantation 201218 334-347. (https://doi.org/10.1016/j.bbmt.2012.01.003) 
8 Rose SR, Horne VE, Howell J, Lawson SA, Rutter MM, Trotman GE $\&$ Corathers SD. Late endocrine effects of childhood cancer. Nature Reviews Endocrinology 201612 319-336. (https://doi.org/10.1038/ nrendo.2016.45)

9 Brennan BM \& Shalet SM. Endocrine late effects after bone marrow transplant. British Journal of Haematology 2002118 58-66. (https:// doi.org/10.1046/j.1365-2141.2002.03527.x)

10 Tauchmanova L, Selleri C, Rosa GD, Pagano L, Orio F, Lombardi G, Rotoli B \& Colao A. High prevalence of endocrine dysfunction in long-term survivors after allogeneic bone marrow transplantation for hematologic diseases. Cancer 200295 1076-1084. (https://doi. org/10.1002/cncr.10773)

11 Savas-Erdeve S, Berberoglu M, Siklar Z, Hacihamdioglu B, Ocal G, Ertem M, Ileri T, Ince EU \& Uysal Z. Primary adrenal insufficiency in a child after busulfan and cyclophosphamide-based conditioning for hematopoietic stem cell transplantation. Journal of Pediatric Endocrinology and Metabolism 201124 853-855. (https;//doi. org/10.1515/JPEM.2011.131)

12 Mellouli F, Ksouri H, Lakhal A, Torjmen L, Ladeb S, Ben Othman T, Hmida S \& Bejaoui M. Autoimmune polyglandular syndrome type II after bone marrow transplant: real transfer or acceleration of a programmed disease? Experimental and Clinical Transplantation 2012 10 76-80. (https://doi.org/10.6002/ect.2011.0062)

13 Latal Hajnal B, Lips U, Friedrich W, Zachmann M \& Berthet F. Addison disease 10 years after bone marrow transplantation for Wiskott-Aldrich syndrome. European Journal of Pediatrics 1995154 729-731. (https://doi.org/10.1007/BF02276716)

14 Cohen A, Rovelli R, Zecca S, Van-Lint MT, Parodi L, Grasso L \& Uderzo C. Endocrine late effects in children who underwent bone marrow transplantation: review. Bone Marrow Transplantation 1998 21 (Supplement 2) S64-S67.

15 Shalet SM, Didi M, Ogilvy-Stuart AL, Schulga J \& Donaldson MD. Growth and endocrine function after bone marrow transplantation. Clinical Endocrinology 199542 333-339. (https://doi. org/10.1111/j.1365-2265.1995.tb02640.x)

16 Ranke MB, Schwarze CP, Dopfer R, Klingebiel T, Scheel-Walter HG, Lang P, Niethammer D \& PDWP of the BMT. Late effects after stem cell transplantation (SCT) in children - growth and hormones. Bone Marrow Transplantation 200535 (Supplement 1) S77-S81. (https:// doi.org/10.1038/sj.bmt.1704853)

17 Bajwa R, Skeens M, Garee A, Miao Y, Soni S, Pietryga D, Gross T \& Termuhlen A. Metabolic syndrome and endocrine dysfunctions after HSCT in children. Pediatric Transplantation 201216 872-878. (https://doi.org/10.1111/petr.12002)

18 Vantyghem MC, Cornillon J, Decanter C, Defrance F, Karrouz W, Leroy C, Le Mapihan K, Couturier MA, De Berranger E, Hermet E, et al. Management of endocrino-metabolic dysfunctions after allogeneic hematopoietic stem cell transplantation. Orphanet Journal of Rare Diseases 20149 162. (https://doi.org/10.1186/s13023-0140162-0)

19 Arlt W. Adrenal insufficiency. Clinical Medicine 20088 211-215. (https://doi.org/10.7861/clinmedicine.8-2-211)

20 Neary N \& Nieman L. Adrenal insufficiency: etiology, diagnosis and treatment. Current Opinion in Endocrinology, Diabetes and Obesity 201017 217-223. (https://doi.org/10.1097/ MED.0b013e328338f608)

21 Betterle C \& Zanchetta R. Update on autoimmune polyendocrine syndromes (APS). Acta Biomedica 2003 74 9-33.
22 Ono Y, Ono S, Yasunaga H, Matsui H, Fushimi K \& Tanaka Y. Clinical features and practice patterns of treatment for adrenal crisis: a nationwide cross-sectional study in Japan. European Journal of Endocrinology 2017176 329-337. (https://doi.org/10.1530/EJE-160803)

23 Pazderska A \& Pearce SH. Adrenal insufficiency - recognition and management. Clinical Medicine 201717 258-262. (https://doi. org/10.7861/clinmedicine.17-3-258)

24 Mackey, JR, Desai S, Larratt L, Cwik V \& Nabholtz JM. Myasthenia gravis in association with allogeneic bone marrow transplantation: clinical observations, therapeutic implications and review of literature. Bone Marrow Transplantation 199719 939-942. (https:// doi.org/10.1038/sj.bmt.1700759)

25 O'Brien TA, Eastlund T, Peters C, Neglia JP, Defor T, Ramsay NK \& Scott Baker K. Autoimmune haemolytic anaemia complicating haematopoietic cell transplantation in paediatric patients: high incidence and significant mortality in unrelated donor transplants for non-malignant diseases. British Journal of Haematology $2004 \mathbf{1 2 7}$ 67-75. (https://doi.org/10.1111/j.1365-2141.2004.05138.x)

26 Williams KM, Dietzen D, Hassoun AA, Fennoy I \& Bhatia M. Autoimmune thyroid disease following alemtuzumab therapy and hematopoietic cell transplantation in pediatric patients with sickle cell disease. Pediatric Blood and Cancer 201461 2307-2309. (https:// doi.org/10.1002/pbc.25102)

27 Bohgaki T, Atsumi T \& Koike T. Multiple autoimmune diseases after autologous stem-cell transplantation. New England Journal of Medicine 2007357 2734-2736. (https://doi.org/10.1056/NEJMc076383)

28 Sherer Y \& Shoenfeld Y. Autoimmune diseases and autoimmunity post-bone marrow transplantation. Bone Marrow Transplantation 1998 22 873-881. (https://doi.org/10.1038/sj.bmt.1701437)

29 Kier P, Penner E, Bakos S, Kalhs P, Lechner K, Volc-Platzer B, Wesierska-Gadek J, Sauermann G, Gadner H, EmmingerSchmidmeier W, et al. Autoantibodies in chronic GVHD: high prevalence of antinucleolar antibodies. Bone Marrow Transplantation 19906 93-96.

30 Wang KS, Kim HT, Nikiforow S, Heubeck AT, Ho VT, Koreth J, Alyea EP, Armand P, Blazar BR, Soiffer RJ, et al. Antibodies targeting surface membrane antigens in patients with chronic graft-versushost disease. Blood 2017130 2889-2899. (https://doi.org/10.1182/ blood-2017-08-801001)

31 Khalil A, Zaidman I, Bergman R, Elhasid R \& Ben-Arush MW. Autoimmune complications after hematopoietic stem cell transplantation in children with nonmalignant disorders. Scientific World Journal 20142014 581657. (https://doi. org/10.1155/2014/581657)

32 Daikeler T, Labopin M, Di Gioia M, Abinun M, Alexander T, Miniati I, Gualandi F, Fassas A, Martin T, Schwarze CP, et al. Secondary autoimmune diseases occurring after HSCT for an autoimmune disease: a retrospective study of the EBMT Autoimmune Disease Working Party. Blood 2011118 1693-1698. (https://doi. org/10.1182/blood-2011-02-336156)

33 Daikeler T \& Tyndall A. Autoimmunity following haematopoietic stem-cell transplantation. Best Practice and Research: Clinical Haematology 200720 349-360. (https://doi.org/10.1016/j. beha.2006.09.008)

34 Bohgaki T, Atsumi T \& Koike T. Autoimmune disease after autologous hematopoietic stem cell transplantation. Autoimmunity Reviews 2008 7 198-203. (https://doi.org/10.1016/j.autrev.2007.11.005) 